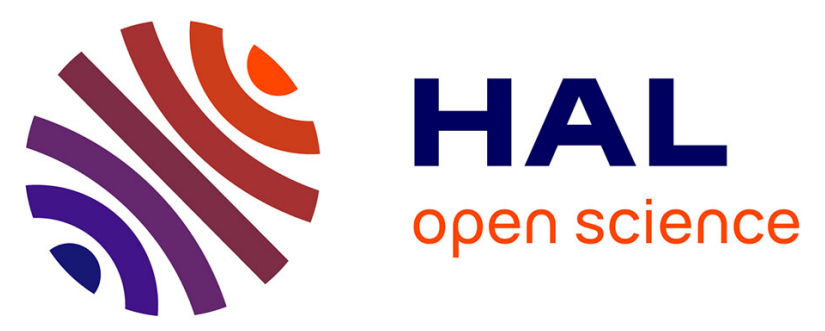

\title{
Evaluation of a biodegradable PLA-PEG-PLA internal biliary stent for liver transplantation: in vitro degradation and mechanical properties
}

Edouard Girard, Grégory Chagnon, Alexandre Moreau-Gaudry, Christian Letoublon, Denis Favier, Stéphane Dejean, Bertrand Trilling, Benjamin

\author{
Nottelet
}

\section{To cite this version:}

Edouard Girard, Grégory Chagnon, Alexandre Moreau-Gaudry, Christian Letoublon, Denis Favier, et al.. Evaluation of a biodegradable PLA-PEG-PLA internal biliary stent for liver transplantation: in vitro degradation and mechanical properties. Journal of Biomedical Materials Research Part B: Applied Biomaterials, 2020, 10.1002/jbm.b.34709 . hal-02961051

\section{HAL Id: hal-02961051 \\ https://hal.science/hal-02961051}

Submitted on 8 Oct 2020

HAL is a multi-disciplinary open access archive for the deposit and dissemination of scientific research documents, whether they are published or not. The documents may come from teaching and research institutions in France or abroad, or from public or private research centers.
L'archive ouverte pluridisciplinaire HAL, est destinée au dépôt et à la diffusion de documents scientifiques de niveau recherche, publiés ou non, émanant des établissements d'enseignement et de recherche français ou étrangers, des laboratoires publics ou privés. 


\section{Evaluation of a biodegradable PLA-PEG-PLA internal biliary stent for liver transplantation: in vitro degradation and mechanical properties.}

Edouard GIRARD ${ }^{1,3, *}$, Grégory CHAGNON ${ }^{2}$, Alexandre MOREAU-GAUDRY ${ }^{1,2}$, Christian LETOUBLON $^{3}$, Denis FAVIER ${ }^{2}$, Stéphane DEJEAN ${ }^{4}$, Bertrand TRILLING ${ }^{1,3}$, Benjamin NOTTELET ${ }^{4, *}$

${ }^{1}$ Univ. Grenoble Alpes, CNRS, Grenoble INP, CHU Grenoble Alpes, TIMC-IMAG, 38000 Grenoble, France

${ }^{2}$ Univ. Grenoble Alpes, CNRS, Grenoble INP, TIMC-IMAG, 38000 Grenoble, France

${ }^{3}$ Département de chirurgie digestive et de l'urgence, Centre Hospitalier Grenoble-Alpes, 38000 Grenoble, France

${ }^{4}$ IBMM, Université de Montpellier, CNRS, ENSCM, Montpellier, France.

\section{* Corresponding authors:}

Dr Edouard GIRARD, Laboratoire TIMC-IMAG, Domaine de la Merci, 38706 La Tronche Cedex, France. Tel: +33 (0)456520086. E-mail address: edouard.girard@ univ-grenoblealpes.fr

Pr Benjamin NOTTELET, Institut des Biomolécules Max Mousseron, UFR Pharmacie, 15 Avenue Charles Flahault, 34093 Montpellier cedex 05, France. Tel: +33 (0)411759697. Email address: benjamin.nottelet@umontpellier.fr

Declarations of interest: none 


\begin{abstract}
Internal biliary stenting during biliary reconstruction in liver transplantation decrease anastomotic biliary complications. Implantation of a Resorbable Internal Biliary Stent (RIBS) is interesting since it would avoid an ablation gesture. The objective of present work was to evaluate adequacy of selected PLA- $b$-PEG- $b$-PLA copolymers for RIBS aimed to secure biliary anastomose during healing and prevent complications such as bile leak and stricture. The kinetics of degradation and mechanical properties of a RIBS prototype were evaluated with respect to the main bile duct stenting requirements in liver transplantation. For this purpose, RIBS degradation under biliary mimicking solution vs. standard phosphate buffer control solution were discussed. Morphological changes, mass loss, water uptake, molecular weight, permeability, $\mathrm{pH}$ variations and mechanical properties were examined over time. The permeability and mechanical properties were evaluated under simulated biliary conditions to explore the usefulness of a PLA- $b$-PEG- $b$-PLA RIBS to secure biliary anastomosis. Results showed no $\mathrm{pH}$ influence on the kinetics of degradation, with degradable RIBS remaining impermeable for at least 8 weeks, and keeping its mechanical properties for 10 weeks. Complete degradation is reached at 6 months. PLA- $b$-PEG- $b$-PLA RIBS have the required in vitro degradation characteristics to secure biliary anastomosis in liver transplantation and envision in vivo applications.
\end{abstract}

\title{
KEYWORDS
}

Liver transplantation; Biliary Fistula; Internal Biliary Stenting; Absorbable Implants;

Polylactide-Polyethylene glycol coplymers; Mechanical properties. 


\section{INTRODUCTION}

Biliary complications in Liver Transplantation (LT) are a significant source of postoperative morbidity and mortality, induce a severe financial burden and may eventually compromise outcomes $^{(1)-(3)}$. Complications arising from the biliary anastomosis (leakage, stricture) are usually considered as the technical Achilles heel of LT. In the literature, incidence of anastomotic biliary complications remains high, ranging from $10 \%$ to $50 \%{ }^{(4)}$. Duct-to-duct reconstruction with an external stent implantation (T-tube) has been the gold standard for many years, however, and although the debate is still open, a growing number of centers have abandoned T-tube placement due to evidences pointing out at specific T-tube induced morbidity (5)-(10). Instead, the use of internal biliary stenting (IBS) has been reported as a safe alternative allowing to decrease anastomotic biliary complications ${ }^{(11)-(14)}$. Although IBS is an interesting option, several technical issues such as the nature of the material (silicone, rubber) require further refinement. In particular, the main disadvantage of the materials currently used is their non-degradability, which leads to an additional surgical procedure for ablation, involving potential complications and an additional cost. For this reason, ideally duct-to-duct reconstruction should be performed with intraoperative insertion of a Resorbable Internal Biliary Stent (RIBS).

To be usable and useful, such RIBS must comply with many specifications (biocompatibility, appropriate mechanical properties etc.). In particular, based on incidence of anastomotic biliary leakage and anastomotic biliary stricture in literature ${ }^{(15),(16)}$, RIBS must be impermeable for a minimum of 4 weeks to prevent bile leak and it must calibrate the anastomosis for 8 weeks to avoid bile duct strictures, and it must be completely degraded within 6 months without release of macroparticles. In this context, biodegradable aliphatic polyesters, including polyglycolide (PGA), polylactide (PLA), and their copolymers (PLGA) are materials of choice and were used for fabrication of resorbable implantable medical devices and scaffolds for tissue engineering 
(17)-(21). Despite of biodegradable stent development in clinical practice for diverse applications, especially vascular $^{(20),(22)}$, only a limited number of studies was realized for biliary system. Xu et al in 2009 investigated degradation of a biodegradable poly(L-lactide-co-glycolide) (PLGA) stent in vitro in bile ${ }^{(23)}$. Physicochemical and mechanical characteristics were compatible with bile duct implantation, but material complete degradation duration was about 4 or 5 weeks, which is not long enough for a LT application. In parallel, PLGA stent degradation in large animals' bile ducts (dog or pig) has been evaluated, which demonstrated good biocompatibility and no bile sludge stent obstruction ${ }^{(24)-(26)}$. In another approach, Tashiro et al. evaluated the use of a poly(L-lactide-co- $\varepsilon$-caprolactone) (L-LA/CL 50:50) biliary stent on a porcine transplant model, and validated a resorption without biliary leak or obstructive cholestasis ${ }^{(27)}$. Most of the proposed materials suffers however from either a fast degradation under bile duct conditions, or inadequate mechanical properties (initially to weak or too rigid). These examples illustrate the prime importance of combined kinetics of degradation and mechanical properties for the material selection. In this frame, tremendous amounts of recent research have therefore focused on the use of PLA/poly(ether) copolymers to modulate these properties for applications ranging from vascular grafts, to nerve guides or bone scaffolds ${ }^{(28)-(32)}$. In particular, some of us demonstrated that PLA-Poloxamer and PLA-Poloxamine triblock copolymers can be good candidates for ligament tissue engineering as, besides ease of processability, their mechanical and degradation properties can be easily tuned to meet the application requirements ${ }^{(33)-(36)}$. In an effort to produce degradable copolymers matching the mechanical properties of softer tissues, we also investigated another family of poly(lactide)- $b$-poly(ethylene glycol)- $b$ poly(lactide) (PLA- $b$-PEG- $b$-PLA) by focusing on the modelling of their mechanical behavior over degradation that was fitted with a non-linear viscoelastic model ${ }^{(37),(38)}$.

Taking advantage of their properties the aim of the present work is therefore to design a RIBS based on a selected PLA- $b$-PEG- $b$-PLA to secure biliary anastomose during healing and avoid 
complications such as bile leak and stricture. In more details, the objectives are to evaluate the mechanical properties of a RIBS prototype with respect to the common bile duct stenting requirements in liver transplantation. For this purpose, the mechanical properties and the permeability are evaluated over degradation under simulated biliary conditions to explore the usefulness of a PLA- $b$-PEG- $b$-PLA RIBS to secure biliary anastomosis.

\section{MATERIALS AND METHODS}

\subsection{Material}

Chemicals were provided by Sigma-Aldrich (Saint-Quentin-Fallavier, France). Phosphatebuffered saline (PBS) was purchased from Invitrogen (Cergy-Pontoise, France). D,L-lactide (D,L-LA) was purchased from Purac (Lyon, France). Solvents and chemicals were used without any further purification. Silicone stent was purchased from Péters Surgical (Bobigny, France).

\subsection{Physicochemical characterization}

${ }^{1} \mathrm{H}$ NMR spectra were recorded with a $300 \mathrm{MHz}$ AMX300 Bruker spectrometer at room temperature. Solvent used was deuterated chloroform, chemical shifts were indicated in ppm with tetramethylsilane (TMS) as a reference.

Number average molecular weight $\left(M_{n}\right)$ and dispersity $(Ð)$ were obtained by Size Exclusion Chromatography (SEC) with a Viscotek GPCMax auto sampler system fitted two Viscotek LT5000L Mixed Medium columns (300 mm x $7.8 \mathrm{~mm}$ ), a Viscotek VE 3580 RI detector. The mobile phase was tetrahydrofuran (THF) at $1 \mathrm{~mL} / \mathrm{min}$ flow and $30^{\circ} \mathrm{C}$. The polymer was dissolved in THF to reach $10 \mathrm{mg} / \mathrm{mL}$ solution that was filtered through a $0.45 \mu \mathrm{m}$ Millipore filter before injection. $M_{n}$ was expressed according to polystyrene standards calibration.

\subsection{Copolymers synthesis and RIBS prototype manufacturing}

Triblock copolymer of PLA- $b$-PEG- $b$-PLA was realized following a previously described procedure $^{(33)}$. In a typical synthesis, predetermined amounts of D,L-LA and PEG were introduced in a round-bottom flask. The catalyst $\mathrm{Sn}(\mathrm{Oct})_{2}$ was then added $(0.1$ molar $\%$ with 
respect to LA units). After degassing, and sealing of the flask under vacuum, the polymerization was allowed to proceed at $110^{\circ} \mathrm{C}$ for 5 days. The copolymer was then recovered by dissolution in dichloromethane (DCM), precipitation in cold diethyl ether, and drying under reduced pressure to constant mass. The copolymer was obtained with a yield of $90 \%$. Polymerization Degree (DP) of each PLA block is defined as:

(1) $D P_{P L A}(\%)=\frac{1}{2} \times \frac{D P_{P E G}}{\frac{E G}{L A}}$

with $E G / L A$ being the ratio of ethylene oxide and lactyl units calculated from ${ }^{1} \mathrm{H}$ NMR spectra, ${ }^{1} \mathrm{H}$ NMR: (300MHz; CDCl3): $\delta(\mathrm{ppm})=5.1(\mathrm{q}, 1 \mathrm{H}, \mathrm{CO}-\mathrm{CH}(\mathrm{CH} 3)-\mathrm{O}), 3.6(\mathrm{~s}, 4 \mathrm{H}, \mathrm{CH} 2-\mathrm{CH} 2-$ O), 1.5 (m, 3H, CO-CH(CH3)-O). $M_{\text {ntribloc }}=345000 \mathrm{~g} / \mathrm{mol}, L A / E G=10 / 1$.

The molecular weight of the achieved triblock copolymers is determined as:

(2) $M_{\text {ntribloc }}(\%)=2 \times\left(D P_{P L A} \times 72\right)+M_{n P E G}$

with $M_{n P E G}=20000 \mathrm{~g} / \mathrm{mol}$.

Polymer films with a targeted thickness of $0.6 \mathrm{~mm}$ (based on commercially available stents) were realized by solvent evaporation. A predetermined polymer quantity was solubilized in acetone, the solution was poured in a small plate and evaporation was realized for $36 \mathrm{~h}$ under an extractor hood. Final solvent removal was produced by further drying in vacuum under $1.10^{-3}$ mbar for 3 days. A $0.5 \mathrm{~mm}$ thick film was produced.

RIBS was then fabricated by film-rolling and gluing by means of a partial dissolution of the polymer film surface. A $45 \mathrm{~mm} \times 1.5 \mathrm{~mm}$ rectangular plate was cut from the film and then wound around a metallic stent with $4.6 \mathrm{~mm}$ external diameter. The gluing was achieved using acetone. RIBS dimensions were: external diameter $5.6 \mathrm{~mm}$, internal diameter $4.6 \mathrm{~mm}$, length $45 \mathrm{~mm}$, an illustration is presented in Figure 1.

\subsection{In vitro degradation studies}


PLA- $b$-PEG- $b$-PLA hydrolytic degradation was investigated under physiological conditions at $37^{\circ} \mathrm{C}$, under stirring $100 \mathrm{rpm}$, and protected from light. In more details, a "control group" was degraded under classical conditions, ie in PBS (pH 7.2) while a "biliary group" was degraded in a simulated bile fluid reproducing bile composition and $\mathrm{pH}(\mathrm{pH}$ 8.4). Biliary $\mathrm{pH}$ physiologically oscillates between 7 and 8.4. To increase probability of finding difference, if any, the most basic $\mathrm{pH}$ was chosen, which corresponds to the worst case scenario in terms of degradation kinetics.

This simulated bile fluid was made according to a Sörensen model by mixing $96.5 \mathrm{~mL}$ of $\mathrm{Na}_{2} \mathrm{HPO}_{4} 133 \mathrm{mmol} / \mathrm{L}\left(23.67 \mathrm{~g} \mathrm{Na}_{2} \mathrm{HPO}_{4}\right.$ per liter of water) with $3.5 \mathrm{~mL}$ of $\mathrm{KH}_{2} \mathrm{PO}_{4} 133$ $\mathrm{mmol} / \mathrm{L}\left(18.10 \mathrm{~g}\right.$ of $\mathrm{KH}_{2} \mathrm{PO}_{4}$ per liter of water) to $100 \mathrm{~mL}$ of solution. The $\mathrm{pH}$ of solutions was tested weekly, and solutions were replaced when it fell below a threshold value $(\mathrm{pH}<7$ for the control group and $\mathrm{pH}<8$ for biliary group).

Measurements at predefined degradation time points were performed in triplicate and expressed as mean values $\pm \mathrm{SD}$.

For mass loss measurement, RIBS were placed in $20 \mathrm{~mL}$ test stents and submitted to 12 weeks of degradation the selected fluid (PBS or 'biliary' fluid according to the group) at $37^{\circ} \mathrm{C}$ within an agitator/incubator. The initial mass $(m o)$ was measured and correspond to the mass of the sample priori to degradation. At given time-points, films were taken out of the solution, weighted, dried and weighted again to obtain the hydrated mass $\left(m_{h y d}\right)$ and the dry mass $\left(m_{d}\right)$. Mass loss and water uptake were then calculated according to:

$$
\begin{array}{r}
\text { Mass loss }(\%)=\frac{m_{0}-m_{d}}{m_{0}} \times 100 \\
\text { Water uptake }(\%)=\frac{m_{h y d}-m_{0}}{m_{0}} \times 100
\end{array}
$$

Finally, in addition to molecular weight and mass loss measurements, macroscopic RIBS observation were made at each degradation time from a surgical point of view by a trained surgeon. Degradation solutions were filtered with a $0.45 \mu \mathrm{m}$ pore size and $47 \mathrm{~mm}$ diameter 
cellulose acetate membrane filter. The membrane filter was then analyzed by microscopy imaging (x40 magnification) to measure the size of particles that may were retained.

\subsection{Permeability test}

Samples used were $0.5 \mathrm{~mm}$ thick and $25 \mathrm{~mm}$ diameter circular polymer films. Permeability of samples was tested using a horizontal diffusion chamber as presented in Figure 2. Two $5 \mathrm{~mL}$ glass compartments were separated by the film to be tested. Seal was made by apposition of a cellulose joint on either side of the polymer film. First chamber was filled with degradation solution, which was maintained at $37^{\circ} \mathrm{C}$. A water column of $20.3 \mathrm{~cm}$ was disposed on the first chamber in order to exert on the plate a $15 \mathrm{mmHg}$ pressure (simulating internal pressure of bile duct). Pressure of $15 \mathrm{mmHg}$ was maintained 24 hours on the plate. To assess porosity, amount of liquid in the second chamber was measured.

\subsection{Mechanical properties measurement}

RIBS samples were put in degradation medium following the protocol described in paragraph 2.4. At defined time-points, compressive mechanical tests were realized at a controlled temperature of $37{ }^{\circ} \mathrm{C}$ on the RIBS over the degradation period. To match with set-up experimental size, RIBS samples of $5 \mathrm{~mm}$ length were tested. The test was run in triplicate for each sample. Mechanical tests consisted in 3 successive cycles, load at strain level 10, 20 and $50 \%$ respectively, with a loading speed rate of $6 \mathrm{~mm} / \mathrm{min}$ followed by an unload with a speed rate of $0.05 \mathrm{~mm} / \mathrm{min}$. Mechanical tests were performed with a Gabo Eplexor mechanical test machine with a load cell of $25 \mathrm{~N}$ at $0,1,2,3,4,6,8$ and 10 weeks of degradation. To measure the strain field, a Digital image correlation software Vic2D was used to measure the section deformation of the RIBS. During mechanical tests, images of the specimens were recorded with a camera at a frequency of $30 \mathrm{~Hz}$. The mechanical work (N.m) to deform the RIBS was evaluated it was calculated by means of the area under the force-displacement curve. 
For comparison, the same mechanical test was applied on a silicone stent (Tubular drain ${ }^{\circledR}$ Péters Surgical, external diameter $5.3 \mathrm{~mm}$, internal diameter $4.8 \mathrm{~mm}$, length segment $5 \mathrm{~mm}$ ) currently used in liver transplantation ${ }^{(11)}$.

\section{RESULTS}

\subsection{Syntheses}

In a preliminary study, we synthesized multiblock copolymers made of amorphous PLA50 (also known as PD,L-LA) and Pluronic ${ }^{\circledR}$, Poloxamer® or PEG by ring-opening polymerization of lactide (Table 1). Based on preliminary evaluation and previous studies (resumed on Table 1), PLA50- $b$-PEG- $b$-PLA50 was selected by a trained surgeon for RIBS development as it showed mechanical and degradation properties corresponding to specifications, assessing material for implantation.

Molecular weights of the copolymers were firstly determined by ${ }^{1} \mathrm{H}$ NMR spectroscopy, by means of Eqs. (1) and (2). Mntribloc was $345000 \mathrm{~g} / \mathrm{mol}$. Results were close to theoretical values mentioned in methods section, although a little higher. On the opposite, SEC analyses gave molecular weight values about two times lower than those calculated by NMR, with an average $M_{\text {ntribloc }}$ at $179000 \mathrm{~g} / \mathrm{mol}$. This difference was explained by the use of polystyrene standards for SEC calibration causing inaccurate measurements with aliphatic polyesters ${ }^{(39),(40)}$. The amphiphilicity of the triblock copolymers, although limited by the low content of PEG, leads to modified hydrodynamic volumes, increased retention times, and results in underestimated values.

\subsection{In vitro degradation}

\subsubsection{Morphological change}

From a macroscopically point of view, during the degradation period, RIBS color gradually changed from an initial translucent state to a whitish color during the first week, and turned opaque white from the second week. From a surgical qualitative point of view, although initially 
relatively flexible before the degradation, the material gradually became stiffer until the $3^{\text {rd }}$ week, before becoming fragile and brittle from the $6^{\text {th }}$ week. After 8 th week, still brittle, it became slightly deformable. Its shape and integrity could not be fully maintained from the 12th week, evolving to a friable and labile consistency, making tests impossible.

The degradation medium was filtered to track the presence of small polymer particles leaching out of the stent bulk upon degradation. No particles were identified on the filters under optical microscope observation at $\times 40$ magnification.

\subsubsection{Mass loss, water uptake and molecular weight}

The mass loss and the water uptake are presented in Figure $\mathbf{3}$ with an exponential function being observed for the polymer water uptake over time. Water uptake was $25 \%$ at 2 weeks, $50 \%$ at 4 weeks, $100 \%$ at 6 weeks, reaching more than $1000 \%$ at 12 weeks. Two distinctive periods are visible. During the three first weeks, the mass loss rate was lower (about 3\% per week) compared to the following weeks (about $10 \%$ per week). After this period, molecular weight decrease was quasi linear. After the 12th week, even if polymers were not fully degraded, weight loss measurements were impossible to perform because of their friable consistency. Unlike mass loss, the molecular weight decrease was very important during the two first weeks as illustrated in Figure 4 with a $60 \%$ decrease. Dispersity index presented in Figure 4 is defined as the ratio of the mass average molecular weight and the number average molecular weight and describes the distribution of molecular mass in a given polymer sample. As expected, the increase of dispersity index follows the decrease of molecular weight. Over the degradation period studied, no significant differences were observed for mass loss, the water uptake and weight loss for the "control group" ( $\mathrm{pH}$ 7.2) and the "biliary group" (pH 8.4).

\subsubsection{Permeability evolution}

The material was impermeable until the 8th week of in vitro degradation. There was no fluid diffusion from 1st to 2 nd chamber, for both groups (control group and biliary group). From the 
10th week, the tests were not practicable because of the fragility of the material at this stage of degradation.

\subsubsection{Influence of $\mathrm{pH}$ variations}

Based on the reported degradation results for RIBS, no significant difference was identified between the two experimental groups. Whether for mass loss, water uptake or molecular weight, as well as for permeability or mechanical behavior.

\subsection{Mechanical properties evolution}

Figure $5 \mathrm{~A}$ presents a typical result of a compression test on a RIBS, the illustration is proposed for 1 degradation week. All curves have the same general appearance. Each deformation cycle was characterized by a load $(10,20$ or $50 \%)$ followed by an unload to zero stress. There was a strength plateau above a strain of $10 \%$ and stiffening after a strain of $30 \%$. Unload could be decomposed into two phases: an instantaneous relaxation corresponding strength fall for a constant strain, and a return to zero stress. Regardless of degradation time, the return phase was constant for all samples, systematically starting at $1 \mathrm{~N}$ force (end of the instantaneous relaxation). The residual strain was $8 \%$ for $10 \%$ strain load, $15 \%$ for $20 \%$ strain load, and $40 \%$ for $50 \%$ strain load. For very large displacements, a strain hardening can be observed meaning that the closures of the RIBS would need a large amount of force. Result of the same mechanical test applied on a silicone stent is presented in Figure 5B. The curve presents a similar level of force for similar deformation, the main difference is that the initial slope is greater for the PLA$b$-PEG- $b$-PLA and that the material presents more hysteresis.

The PLA- $b$-PEG- $b$-PLA curve evolves with the degradation process. The slopes of curves (represented by red arrows on Figure 4A) was evaluated for each deformation cycle at 10, 20 and $50 \%$ and measured for each degradation time. The results are presented in Figure 6. It appears that the stiffness of the RIBS is first increasing during three weeks and is then continuously decreasing until 10 weeks. 
To measure the influence of the hysteresis of the material, the evolution of the work necessary to load and unload the material at 10, 20 and 50\% was calculated, the result is presented in Figure 7. As for the stiffness, the amount of work becomes greater after some weeks before drastically decreasing, illustrating the loss of mechanical properties. Work curves decrease was more important than the stiffness one.

\section{DISCUSSION}

In an attempt to provide an alternative to RIBS that have poor mechanical properties or inadequate degradation (too slow for PCL or crystalline PLA, too fast for PLGA), we synthesized in a preliminary study multiblock copolymers made of amorphous PLA50 and Pluronic ${ }^{\circledR}$, Poloxamer ${ }^{\circledR}$ or PEG (Table 1). In a previous study, we reported that this strategy allows to finely control the properties of the obtained copolymers such as their crystallinity, glass transition temperature, degradation kinetics ${ }^{(33)}$. This makes it possible to find the best match between the requirements of an application and suitable copolymers. Based on preliminary evaluation and previous studies (resumed on Table 1 ), PLA50- $b$-PEG- $b$-PLA50 was selected by a trained surgeon for RIBS development as it showed mechanical and degradation properties corresponding to specifications, assessing material for implantation (flexibility after drying, low Young's modulus and in vivo estimated degradation time of about 6 months for a complete resorption). The aim of the present work was to design a PLA- $b$-PEG- $b$-PLA RIBS to secure biliary anastomose during healing and avoid complications such as bile leak and stricture. We evaluated the mechanical properties of a RIBS prototype with respect to the common bile duct stenting requirements in liver transplantation. For this purpose, the mechanical properties and the permeability are evaluated over degradation under simulated biliary conditions to explore the usefulness of a PLA- $b$-PEG- $b$-PLA RIBS to secure biliary anastomosis. Of notice, we chose to only take $\mathrm{pH}$ into account in our simulated biliary 
conditions but not viscosity. Viscosity is an important parameter of bile that changes as a function of the flow. However, it has been reported that for the $65 \%$ of patients the viscosity of bile under flow from the common bile duct is between water viscosity $(0.7 \mathrm{mPa} . \mathrm{s})$ and the lower limit of plasma viscosity (1.1 mPa.s), and that cholecystectomized patients (as in transplant) had a lower bile viscosity ${ }^{(41),(42)}$. Bile viscosities did not differ according to pathologies (choledocholithiasis, cholangitis, biliary pancreatitis, carcinoma, or transplant). Our study being centered on the in vitro degradation characteristics in a static context with aqueous buffers, the viscosity has therefore not been further considered.

Regarding morphological change, color change is due to the presence of water domains in the polymer matrix whose size and number affects the whitening effect that increases with immersion/degradation time ${ }^{(43)}$.

In order to evaluate the risk of bile duct obstruction the degradation medium was filtered to track the presence of small polymer particles leaching out of the stent bulk upon degradation. The Oddi sphincter size is about a millimeter. There was thus no production of millimeter particles during degradation that could potentially be responsible for a biliary obstacle.

The mass loss gave information about water soluble oligomers generated during the hydrolysis process and released out of the polymer bulk. Two distinctive periods are visible. During the three first weeks, the mass loss rate was lower compared to the following weeks. This induction period is commonly observed during the degradation of aliphatic polyesters and is due to the difficulty, at first, for the degraded chains to diffuse out of the sample ${ }^{(33),(44)}$. After this period, the lower molecular weight and therefore lower entanglement allow the leaching of the degradation products in the degradation medium, which leads to a quasi-linear weight decrease. Unlike mass loss, the molecular weight decrease was very important during the two first weeks. This trend is explained by the highest concentration of ester bonds per volume unit leading to a greater ability of long chains to be hydrolyzed ${ }^{(45)}$. In final steps, probability of scission and 
hydrolysis ratio practically doesn’t exist because of very low ester bonds concentration. As expected, the increase of dispersity index follows the decrease of molecular weight. These results highlight the rise of dispersion of chain lengths due to the random scissions of polymer chains that occur during the degradation process. After the 12th week, even if polymers were not fully degraded, weight loss measurements were impossible to perform because of their friable consistency. Polyester-polyether block copolymers degradation is known to proceed via a bulk erosion, with random polymer chains scissions. The chains became progressively shorter during degradation, releasing soluble oligomers in the media. While keeping its original shape, polymer sample became therefore more brittle.

The material was impermeable until the 8th week of in vitro degradation. Based on incidence of anastomotic biliary leakage in literature ${ }^{(15),(15),(16)}$, to prevent bile leak, RIBS must be impermeable for a minimum of 4 weeks. Specifications were respected on this point.

Based on the reported degradation results for RIBS, no significant difference was identified between the two experimental groups. The $\mathrm{pH}$ difference between the 2 study groups (i.e. "control group" with a $7.2 \mathrm{pH}$ solution vs "biliary group" with an $8.4 \mathrm{pH}$ solution) was too small to induce basic catalysis in biliary group. These results are confirmed by literature data, for acid or basic catalysis, $\mathrm{pH}$ differences must be higher, respectively less than 3 or more than $10^{(46),(47)}$. Physiological bile $\mathrm{pH}$ variations are between 7 and $8.4^{(48)}$. As a result, these biliary $\mathrm{pH}$ variations have no impact on RIBS degradation kinetics, the selected PLA- $b$-PEG- $b$-PLA copolymer can stand the more alkaline conditions found in the common bile duct.

The mechanical comparison between silicone stent and RIBS is not obvious. The curve presents a similar level of force for similar deformation, the main difference is that the initial slope is greater for the PLA- $b$-PEG- $b$-PLA and that the material presents more hysteresis. The silicone stent is efficient to solve the clinical problem but not perfect, the PLA- $b$-PEG- $b$-PLA having closed stiffness must be also a good candidate, but with different mechanical properties as 
hysteresis and the stress plateau. The observed evolution of RIBS stiffness, but also color changes can be explained as follows. It appears that the stiffness of the RIBS is first increasing during three weeks due to microphase separation in copolymers and is then continuously decreasing until 10 weeks, illustrating the normal degradation process. In triblock copolymer PLA- $b$-PEG- $b$-PLA, PEG short blocks have a role of plasticizer and chains mobility and phase separation are facilitated by the water uptake that plasticizes the polymer. In the case of PLA$b$-PEG- $b$-PLA, this water uptake leads to micro-phase separation of the PLA and PEG blocks, which results in the fact that the plasticization of long PLA blocks by the short PEG blocks (more flexible with lower transition temperature) loses its effectiveness at the beginning of degradation ${ }^{(49),(50)}$. Evolution of polymer properties during the first 3 weeks can therefore be explained by 2 phenomena. First, water uptake causes material whitening and a little plasticization ${ }^{(43)}$. In the present case, this plasticization effect is not perceptible because it is associated with the second phenomenon of micro-phase separation. This phenomenon in the triblock copolymers, results in a loss of plasticization of the PLA long blocks by the PEG short blocks, and in a stiffening of the structure ${ }^{(50)}$. This stiffening continues during degradation until separations phases are complete, or until degradation becomes preponderant. This last point is eased by the molecular weight decrease observed during the first 3 weeks (Figure 4, 50\% decrease) that facilitate micro-domains rearrangements. Evolution of the work necessary to load and unload the material at 10, 20 and $50 \%$ was calculated to measure the influence of the hysteresis of the material. As for the stiffness, the amount of work becomes greater after some weeks before drastically decreasing, illustrating the loss of mechanical properties. Work curves decrease was more important than the stiffness one. During degradation, polymer chains were shortened, but kept a good stiffness modulus. While properties with large deformation (illustrated by work) were lowered because of untangled chains. The loss of mechanical properties is not important between the first and the eighth week ensuring the keep of enough 
mechanical properties of the RIBS and its efficiency. But as seen previously (Figure 4), after 10 weeks, the polymer has lost more than $90 \%$ of its initial molecular weight, making mechanical tests impossible due to the extreme brittleness of the specimens. Finally, after 10 weeks, the material would lose the main part of the mechanical properties, meaning that the mechanical resistance should be performed by the constructs composed of infiltrated cells and remaining components of the RIBS.

\section{CONCLUSION}

In present study, we chose PLA- $b$-PEG- $b$-PLA as RIBS due to mechanical and degradation properties corresponding to the specifications required for biliary stents. We found no influence of $\mathrm{pH}$ on the kinetics of degradation for PBS ( $\mathrm{pH} 7.2)$ and simulated bile fluid ( $\mathrm{pH} 8.4$ ), with in particular the material remaining impermeable for at least 8 weeks, and keeping its mechanical properties for 10 weeks. In vitro degradation was complete at 6 months. Results of present study proved that PLA- $b$-PEG- $b$-PLA RIBS had the required in vitro degradation characteristics to secure the biliary anastomosis in liver transplantation. In vitro results will be used as a guideline for planning later in vivo studies.

\section{Compliance with Ethical Standards:}

- Conflict of Interest: The authors declare that they have no conflict of interest.

- This research did not receive any specific grant from funding agencies in the public, commercial, or not-for-profit sectors.

Ackowlegments: M-P. Montmasson for the simulated bile fluid, J-P. Alcaraz for the horizontal diffusion chamber, S. Hunger for the size exclusion chromatography tests, G. Machado and Q. Breche for help for mechanical tests. 


\section{REFERENCES}

1. Welling TH, Heidt DG, Englesbe MJ, Magee JC, Sung RS, Campbell DA, Punch JD, Pelletier SJ. Biliary complications following liver transplantation in the model for end-stage liver disease era: Effect of donor, recipient, and technical factors. Liver Transpl. 2008;14:73-80.

2. Seehofer D, Eurich D, Veltzke-Schlieker W, Neuhaus P. Biliary Complications After Liver Transplantation: Old Problems and New Challenges. Am J Transplant. 2013;13:253-65.

3. Akamatsu N, Sugawara Y, Hashimoto D. Biliary reconstruction, its complications and management of biliary complications after adult liver transplantation: a systematic review of the incidence, risk factors and outcome. Transpl Int Off J Eur Soc Organ Transplant. 2011;24:379-92.

4. Goumard C, Cachanado M, Herrero A, Rousseau G, Dondero F, Compagnon P, Boleslawski E, Mabrut JY, Salamé E, Soubrane O, Simon T, Scatton O. Biliary reconstruction with or without an intraductal removable stent in liver transplantation: study protocol for a randomized controlled trial. Trials. 2015;16:598.

5. Riediger C, Müller MW, Michalski CW, Hüser N, Schuster T, Kleeff J, Friess H. T-tube or no Ttube in reconstruction of the biliary tract during orthotopic liver transplantation - systematic review and meta-analysis. Liver Transpl. 2010;NA-NA.

6. Shimoda M, Saab S, Morrisey M, Ghobrial RM, Farmer DG, Chen P, Han S-HB, Bedford RA, Goldstein LI, Martin P, others. A cost-effectiveness analysis of biliary anastomosis with or without T-tube after orthotopic liver transplantation. Am J Transplant. 2001;1:157-161.

7. Scatton O, Meunier B, Cherqui D, Boillot O, Sauvanet A, Boudjema K, Launois B, Fagniez PL, Belghiti J, Wolff P, Houssin D, Soubrane O. Randomized trial of choledochocholedochostomy with or without a T tube in orthotopic liver transplantation. Ann Surg. 2001;233:432-7.

8. Sotiropoulos GC, Sgourakis G, Radtke A, Molmenti EP, Goumas K, Mylona S, Fouzas I, Karaliotas C, Lang H. Orthotopic Liver Transplantation: T-Tube or Not T-Tube? Systematic Review and Meta-Analysis of Results. Transplantation. 2009;87:1672-80.

9. Paes-Barbosa FC, Massarollo PC, Bernardo WM, Ferreira FG, Barbosa FK, Raslan M, Szutan LA. Systematic review and meta-analysis of biliary reconstruction techniques in orthotopic deceased donor liver transplantation. J Hepato-Biliary-Pancreat Sci. 2010;18:525-36.

10. Amador A, Charco R, Martí J, Navasa M, Rimola A, Calatayud D, Rodriguez-Laiz G, Ferrer J, Romero J, Ginesta C, Fondevila C, Fuster J, García-Valdecasas JC. Clinical trial on the cost-effectiveness of T-tube use in an established deceased donor liver transplantation program. Clin Transplant. 2007;21:548-53.

11. Girard E, Risse O, Abba J, Medici M, Leroy V, Chirica M, Letoublon C. Internal biliary stenting in liver transplantation. Langenbecks Arch Surg. 2018;

12. Tranchart H, Zalinski S, Sepulveda A, Chirica M, Prat F, Soubrane O, Scatton O. Removable intraductal stenting in duct-to-duct biliary reconstruction in liver transplantation. Transpl Int. 2012;25:1924.

13. Johnson MW, Thompson P, Meehan A, Odell P, Salm MJ, Gerber DA, Zacks SL, Fried MW, Shrestha R, Fair JH. Internal biliary stenting in orthotopic liver transplantation. Liver Transplant Off Publ Am Assoc Study Liver Dis Int Liver Transplant Soc. 2000;6:356-61.

14. Barkun JS, Tzimas GN, Cantarovich M, Metrakos PP, Deschênes M, Alpert E, Paraskevas S, Tchervenkov JI. Do biliary endoprostheses decrease biliary complications after liver transplantation? Transplant Proc. 2003;35:2435-7.

15. Gursimran Kochhar JMP Ibrahim A Hanouneh, Mansour A Parsi. Biliary complications following liver transplantation. World J Gastroenterol. 2013;19:6.

16. Nemes B, Gámán G, Doros A. Biliary complications after liver transplantation. Expert Rev Gastroenterol Hepatol. 2015;9:447-66.

17. Middleton JC, Tipton AJ. Synthetic biodegradable polymers as orthopedic devices. Biomaterials. 2000;21:2335-46.

18. Tokar JL, Banerjee S, Barth BA, Desilets DJ, Kaul V, Kethi SR, Pedrosa MC, Pfau PR, Pleskow DK, Varadarajulu S, Wang A, Wong Kee Song L-M, Rodriguez SA. Drug-eluting/biodegradable stents. Gastrointest Endosc. 2011;74:954-8.

19. Li J, Zhu J, He T, Li W, Zhao Y, Chen Z, Zhang J, Wan H, Li R. Prevention of intra-abdominal adhesion using electrospun PEG/PLGA nanofibrous membranes. Mater Sci Eng C Mater Biol Appl. 2017;78:988-97.

20. Rogacka R, Chieffo A, Latib A, Colombo A. Bioabsorbable and biocompatible stents. Is a new revolution coming? Minerva Cardioangiol. 2008;56:483-91. 
21. Yaszemski M. Evolution of bone transplantation: molecular, cellular and tissue strategies to engineer human bone. Biomaterials. 1996;17:175-85.

22. Brown DA, Lee EW, Loh CT, Kee ST. A New Wave in Treatment of Vascular Occlusive Disease: Biodegradable Stents—Clinical Experience and Scientific Principles. J Vasc Interv Radiol. 2009;20:315_ 24.

23. Xu X, Liu T, Liu S, Zhang K, Shen Z, Li Y, Jing X. Feasibility of biodegradable PLGA common bile duct stents: an in vitro and in vivo study. J Mater Sci Mater Med. 2009;20:1167-73.

24. Xu X, Liu T, Liu S, Zhang K, Shen Z, Li Y, Jing X. Feasibility of biodegradable PLGA common bile duct stents: an in vitro and in vivo study. J Mater Sci Mater Med. 2009;20:1167-1173.

25. Meng B, Wang J, Zhu N, Meng Q-Y, Cui F-Z, Xu Y-X. Study of biodegradable and selfexpandable PLLA helical biliary stent in vivo and in vitro. J Mater Sci Mater Med. 2006;17:611-617.

26. Laukkarinen J, Nordback I, Mikkonen J, Kärkkäinen P, Sand J. A novel biodegradable biliary stent in the endoscopic treatment of cystic-duct leakage after cholecystectomy. Gastrointest Endosc. 2007;65:1063-8.

27. Tashiro H, Ogawa T, Itamoto T, Ushitora Y, Tanimoto Y, Oshita A, Amano H, Asahara T. Synthetic bioabsorbable stent material for duct-to-duct biliary reconstruction. J Surg Res. 2009;151:85-8. 28. Tara S, Kurobe H, Rocco KA, Maxfield MW, Best CA, Yi T, Naito Y, Breuer CK, Shinoka T. Well-organized neointima of large-pore poly(L-lactic acid) vascular graft coated with poly(L-lactic-co-\&caprolactone) prevents calcific deposition compared to small-pore electrospun poly(L-lactic acid) graft in a mouse aortic implantation model. Atherosclerosis. 2014;237:684-91.

29. Wissing TB, Bonito V, Bouten CVC, Smits AIPM. Biomaterial-driven in situ cardiovascular tissue engineering-a multi-disciplinary perspective. NPJ Regen Med. 2017;2:18.

30. Lins LC, Wianny F, Livi S, Hidalgo IA, Dehay C, Duchet-Rumeau J, Gérard J-F. Development of Bioresorbable Hydrophilic-Hydrophobic Electrospun Scaffolds for Neural Tissue Engineering.

Biomacromolecules. 2016;17:3172-87.

31. Du J, Chen H, Qing L, Yang X, Jia X. Biomimetic neural scaffolds: a crucial step towards optimal peripheral nerve regeneration. Biomater Sci. 2018;6:1299-311.

32. Bhaskar B, Owen R, Bahmaee H, Wally Z, Sreenivasa Rao P, Reilly GC. Composite porous scaffold of PEG/PLA support improved bone matrix deposition in vitro compared to PLA-only scaffolds. J Biomed Mater Res A. 2018;106:1334-40.

33. Leroy A, Pinese C, Bony C, Garric X, Noël D, Nottelet B, Coudane J. Investigation on the properties of linear PLA-poloxamer and star PLA-poloxamine copolymers for temporary biomedical applications. Mater Sci Eng C Mater Biol Appl. 2013;33:4133-9.

34. Leroy A, Nottelet B, Bony C, Pinese C, Charlot B, Garric X, Noël D, Coudane J. PLApoloxamer/poloxamine copolymers for ligament tissue engineering: sound macromolecular design for degradable scaffolds and MSC differentiation. Biomater Sci. 2015;3:617-26.

35. Pinese C, Leroy A, Nottelet B, Gagnieu C, Coudane J, Garric X. Rolled knitted scaffolds based on PLA-pluronic copolymers for anterior cruciate ligament reinforcement: A step by step conception: ROLLED KNITTED SCAFFOLDS. J Biomed Mater Res B Appl Biomater. 2017;105:735-43.

36. Pinese C, Gagnieu C, Nottelet B, Rondot-Couzin C, Hunger S, Coudane J, Garric X. In vivo evaluation of hybrid patches composed of PLA based copolymers and collagen/chondroitin sulfate for ligament tissue regeneration: Hybrid Patches for Ligament Reconstruction. J Biomed Mater Res B Appl Biomater. 2017;105:1778-88.

37. Breche Q, Chagnon G, Machado G, Girard E, Nottelet B, Garric X, Favier D. Mechanical behaviour's evolution of a PLA-b-PEG-b-PLA triblock copolymer during hydrolytic degradation. J Mech Behav Biomed Mater. 2016;60:288-300.

38. Breche Q, Chagnon G, Machado G, Nottelet B, Garric X, Girard E, Favier D. A non-linear viscoelastic model to describe the mechanical behavior's evolution of biodegradable polymers during hydrolytic degradation. Polym Degrad Stab. 2016;131:145-56.

39. Kowalski A, Duda A, Penczek S. Polymerization of L, L -Lactide Initiated by Aluminum Isopropoxide Trimer or Tetramer. Macromolecules. 1998;31:2114-22.

40. Huang M-H, Li S, Vert M. Synthesis and degradation of PLA-PCL-PLA triblock copolymer prepared by successive polymerization of $\varepsilon$-caprolactone and dl-lactide. Polymer. 2004;45:8675-81.

41. Reinhart WH, Näf G, Werth B. Viscosity of human bile sampled from the common bile duct. Clin Hemorheol Microcirc. 2010;44:177-82.

42. McMaster P. Bile studies after liver transplantation. Ann R Coll Surg Engl. 1979;61:435-40.

43. Jiang B, Tsavalas JG, Sundberg DC. Water whitening of polymer films: Mechanistic studies and 
comparisons between water and solvent borne films. Prog Org Coat. 2017;105:56-66.

44. Li SM, Garreau H, Vert M. Structure-property relationships in the case of the degradation of massive aliphatic poly-( $\alpha$-hydroxy acids) in aqueous media. J Mater Sci Mater Med. 1990;1:123-130.

45. Wang Y, Pan J, Han X, Sinka C, Ding L. A phenomenological model for the degradation of biodegradable polymers. Biomaterials. 2008;29:3393-401.

46. Chu CC. The effect of $\mathrm{pH}$ on the in vitro degradation of poly(glycolide lactide) copolymer absorbable sutures. J Biomed Mater Res. 1982;16:117-24.

47. Tsuji H, Ikada Y. Properties and morphology of poly(L-lactide). II. hydrolysis in alkaline solution. J Polym Sci Part Polym Chem. 1998;36:59-66.

48. Esteller A. Physiology of bile secretion. World J Gastroenterol. 2008;14:5641.

49. Kissel T, Li Y, Unger F. ABA-triblock copolymers from biodegradable polyester A-blocks and hydrophilic poly (ethylene oxide) B-blocks as a candidate for in situ forming hydrogel delivery systems for proteins. Adv Drug Deliv Rev. 2002;54:99-134.

50. Lu DD, Yuan JC, Li H, Lei Z-Q. Synthesis and characterization of a series of biodegradable and biocompatible PEG-supported poly(lactic-ran-glycolic acid) amphiphilic barbell-like copolymers. J Polym Sci Part Polym Chem. 2008;46:3802-12.

\section{FIGURE LEGENDS:}
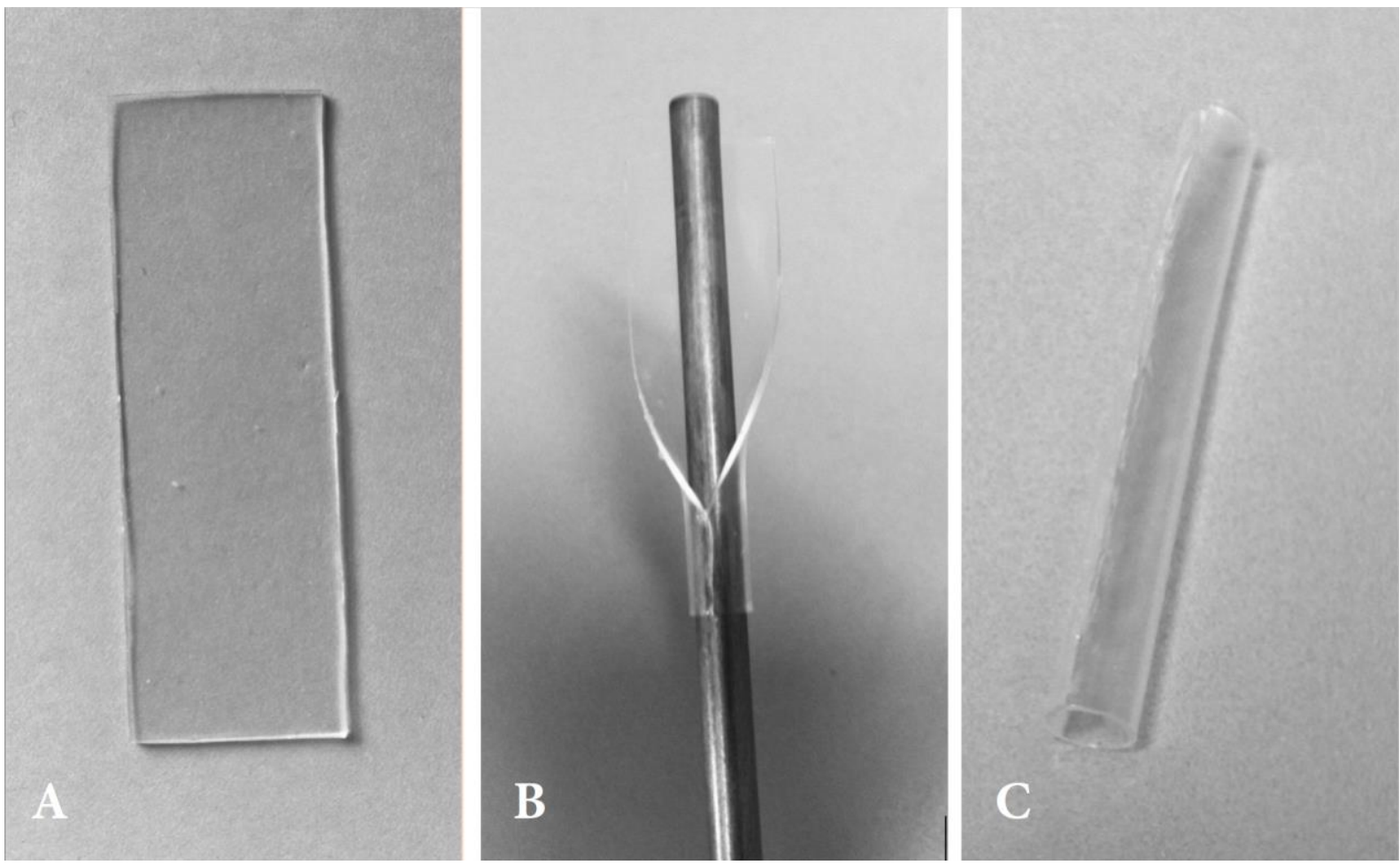

\section{Figure 1:}

RIBS manufacturing. A- Films made by solvent evaporation. B- Film-rolling and gluing thanks to a partial dissolution of the polymer film edges. C- Finalized RIBS. 

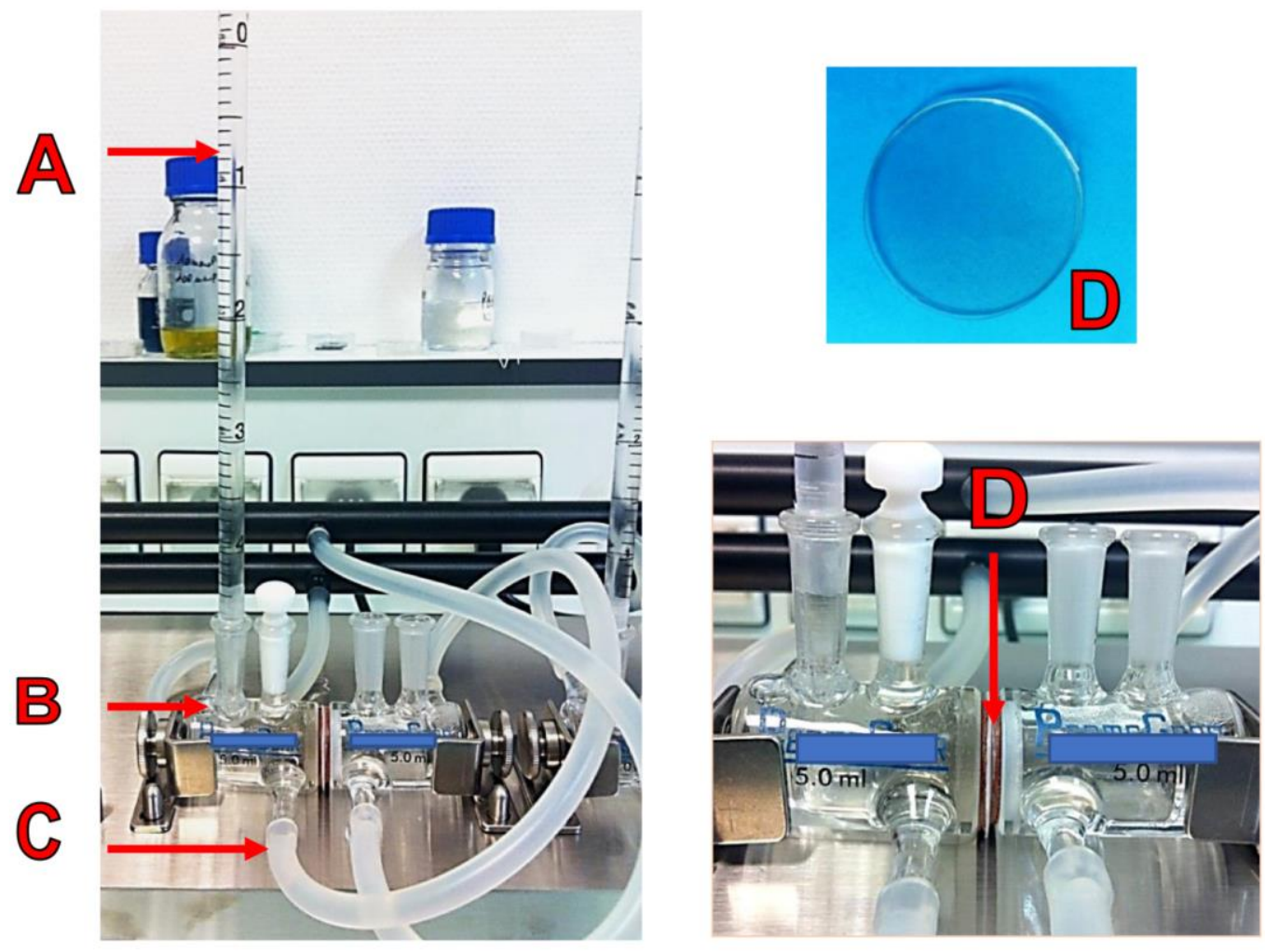

\section{Figure 2:}

Horizontal diffusion chamber. A: water column, B: diffusion chamber with degradation fluid, C: $37^{\circ} \mathrm{C}$ independent liquid circuit. D: Sample to test, surrounded by cellulose joints.

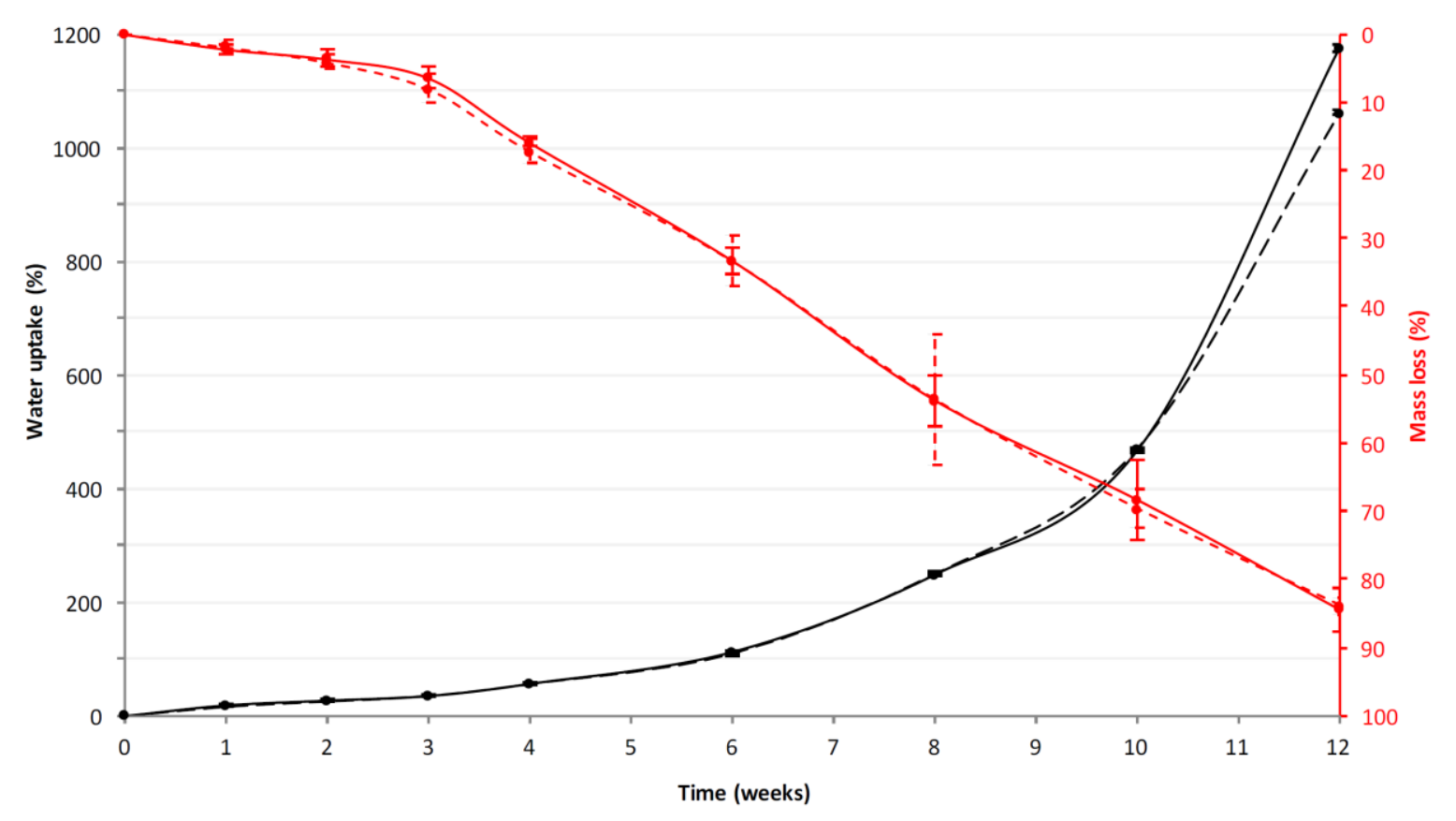

\section{Figure 3:}

Weight loss and water uptake of PLA- $b$-PEG- $b$-PLA triblock copolymer during 12 weeks of degradation at $37^{\circ} \mathrm{C}$. Solid line: 'control group' with PBS (pH 7.2) as degradation solution, 
dotted line: 'biliary group' with bile like serum ( $\mathrm{pH} 8.4$ ). (Data are represented as means $\pm S D$ with $n=3$ ).

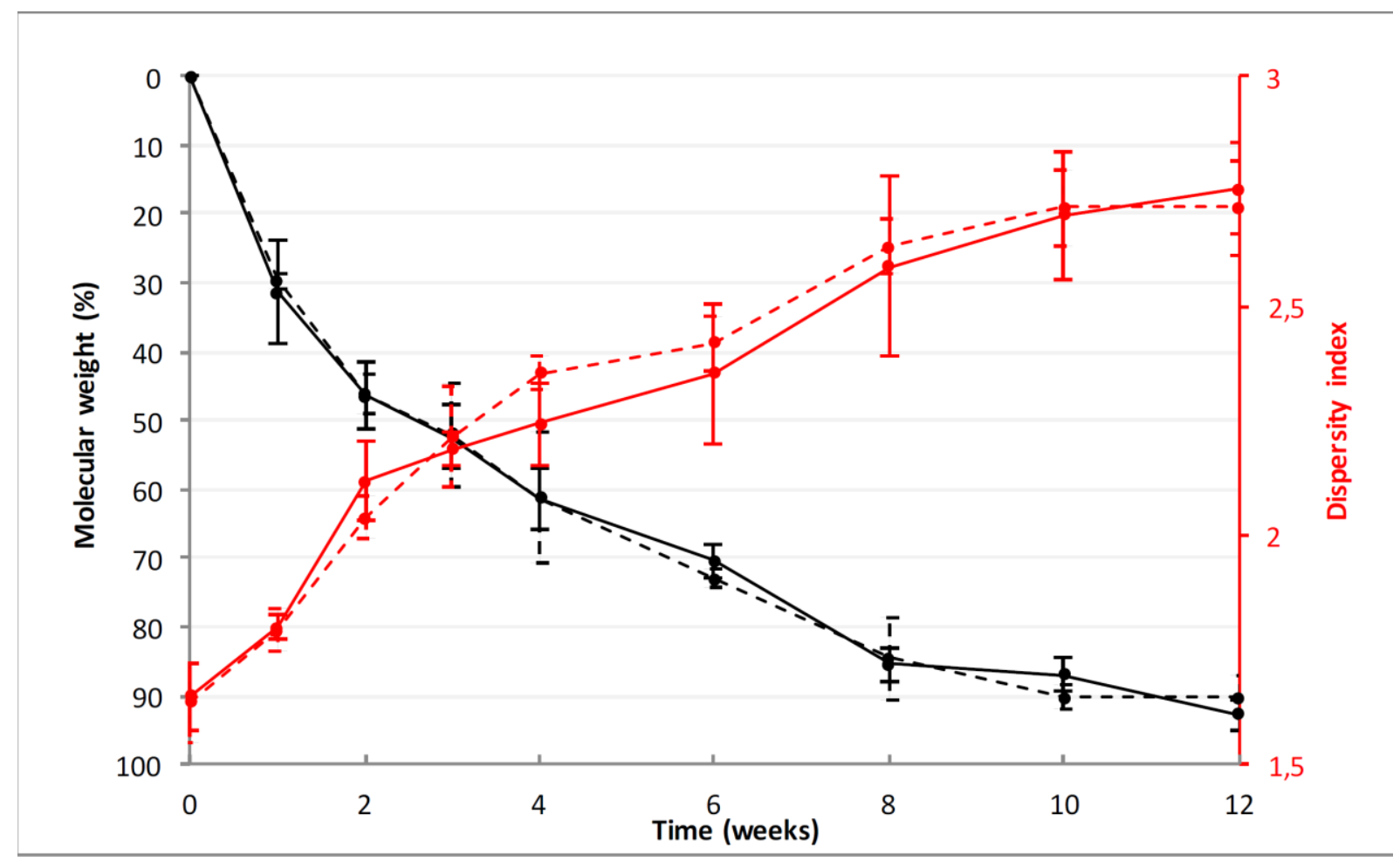

\section{Figure 4:}

Molecular weight and dispersity index evolution of PLA- $b$-PEG- $b$-PLA triblock copolymer during 12 weeks of degradation at $37^{\circ} \mathrm{C}$. Solid line: 'control group' with PBS (pH 7.2) as degradation solution, dotted line: 'biliary group' with bile like serum ( $\mathrm{pH} 8.4)$. (Data are represented as means $\pm S D$ with $n=3$ ). 

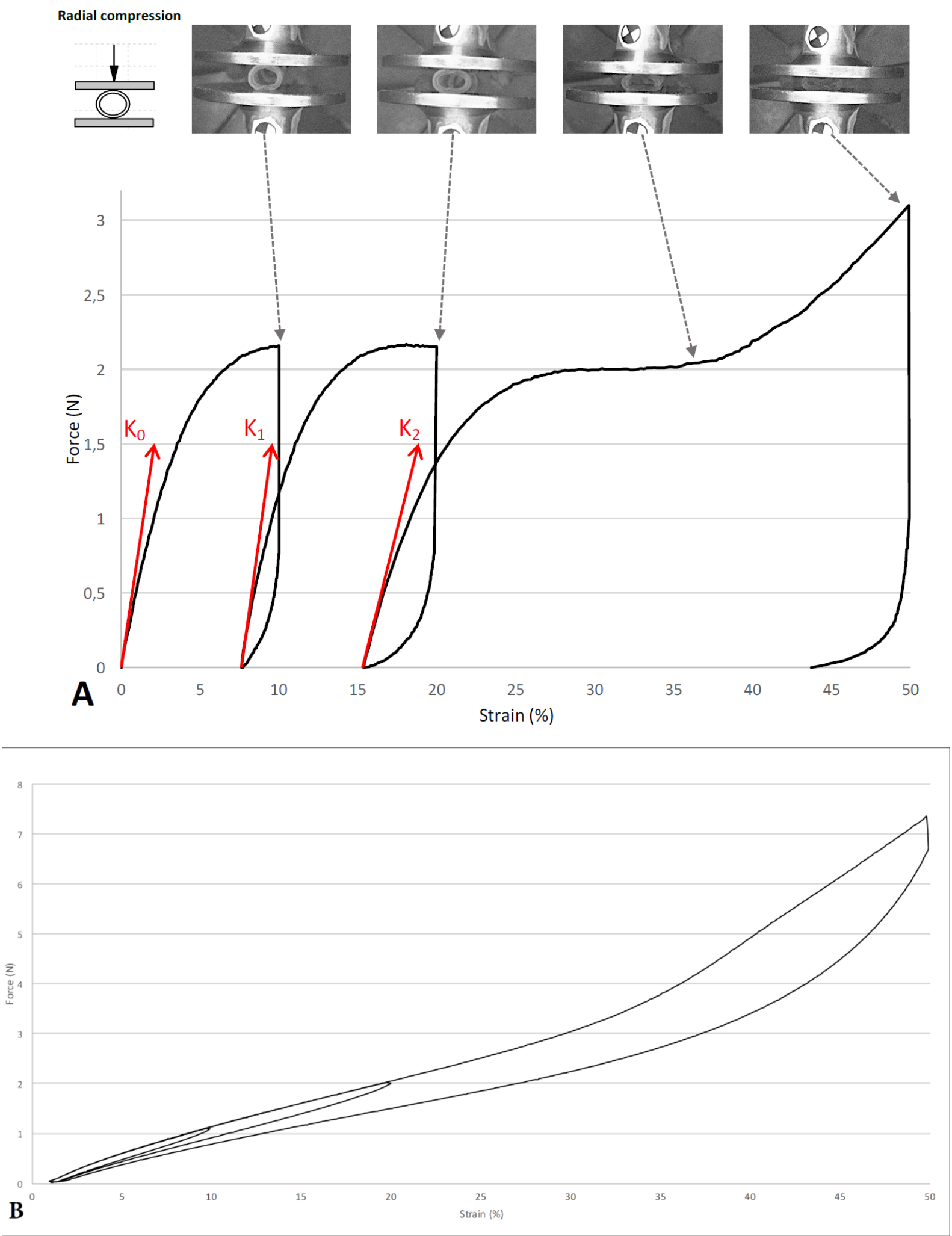

\section{Figure 5:}

Mechanical compression tests: 3 successive cycles with load at 10, 20 and 50\% strain level, followed by an unload to zero strain.

A. Typical result of radial compression test on a RIBS. Stiffness (slope of curve at the origin in red) evaluated for each deformation cycle.

B. Same mechanical test applied on a silicone stent segment. 


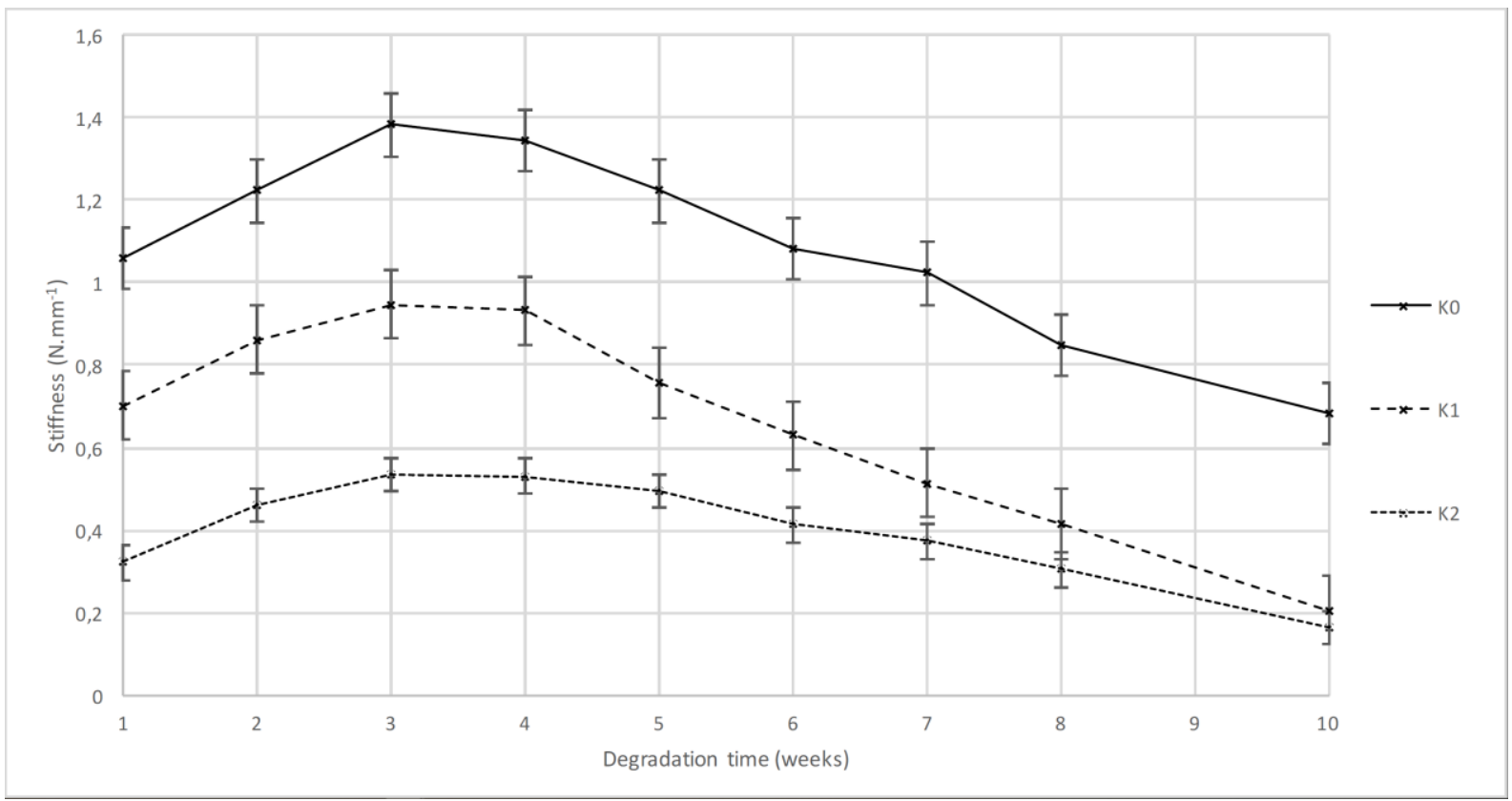

\section{Figure 6:}

Stiffness (K) for RIBS mechanical compression tests during degradation, for different strain cycles.

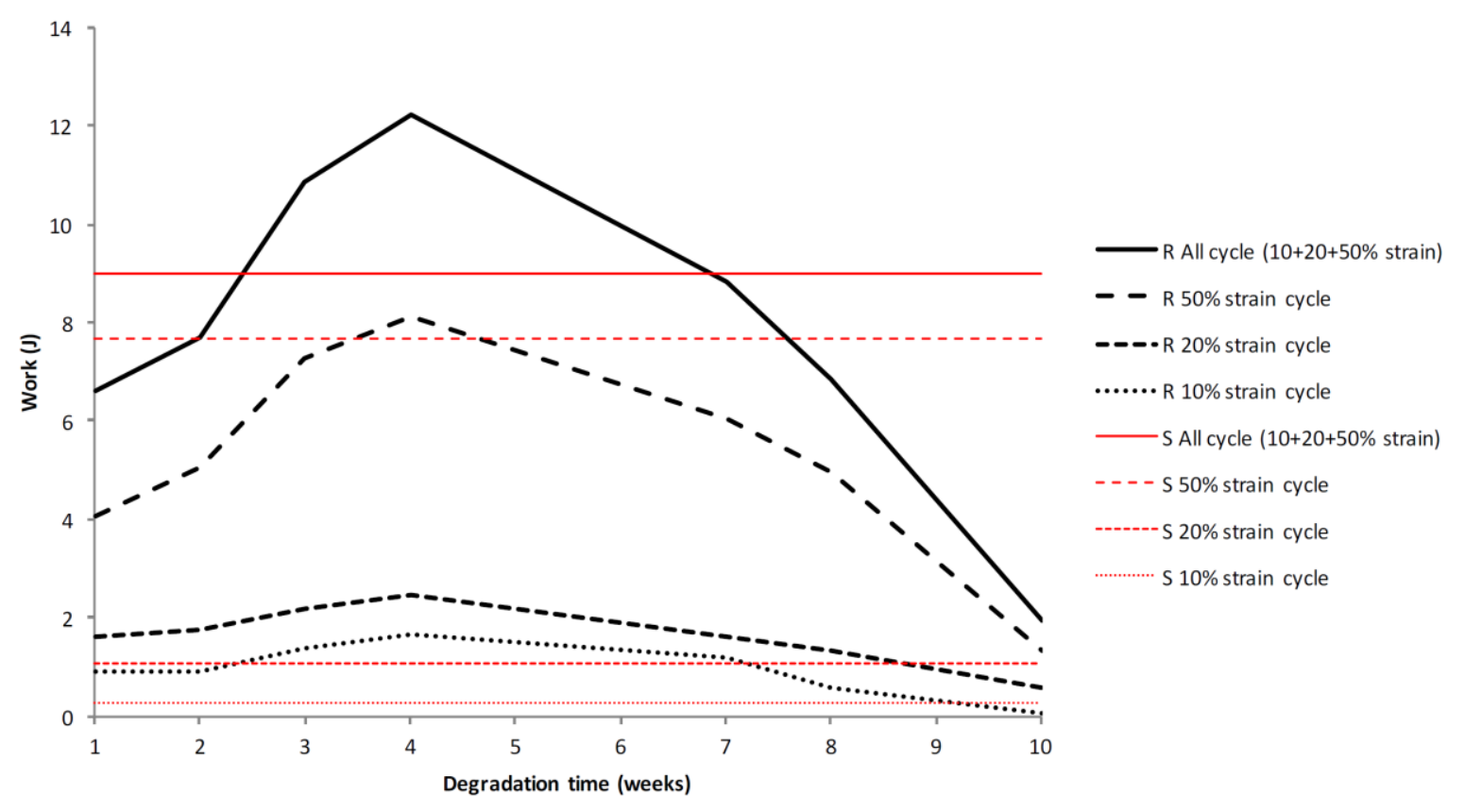

\section{Figure 7:}

RIBS compressive mechanical tests. Work evolution during degradation for RIBS (R) in black, compare to work for silicone stent (S) in red. 